\title{
Degradation Degree of Polyphenols Depending on Drying Temperature of the Grape Pomace
}

\author{
Silvia M. PASCARIU*, Ioan M. POP, Aida ALBU \\ Faculty of Animal Husbandry, University of Agricultural Sciences and Veterinary Medicine, \\ 3 Mihail Sadoveanu Alley, 700490 Iaşi, Romania \\ *Corresponding author, email: pascariu_silvia@yahoo.com \\ Bulletin UASVM Animal Science and Biotechnologies 71(2) / 2014, \\ Print ISSN 1843-5262; Electronic ISSN 1843-536X \\ DOI: $10.15835 /$ buasvmcn-asb:10311
}

\begin{abstract}
Grape pomace provides a rich source of polyphenols, which have the capacity to act as powerful antioxidants. Grape pomace has been used mainly in ruminant feed as a source of fiber and for broiler chickens as a source of antioxidants. It has been proved that the polyphenols from grape pomace are discomposed during the drying process. Taking into consideration the incertitude of polyphenols thermal degradation, the aim of this study was to identify the polyphenols degree of degradation during the drying step at different temperatures. Red grape pomace (Black Maiden) from the same source was dried at room temperature $\left(20^{\circ} \mathrm{C}\right)$ five days and three days at $38^{\circ} \mathrm{C}$ and $50^{\circ} \mathrm{C}$. The total content of polyphenols (TP), tannins (Ta) and anthocyanins (An) was determined by different colorimetric methods. Our data reveal a significant degradation of the TP and An for all the three thermal variants. The Ta and non-adsorbed polyphenols on casein show a high degree of correlation, but with significant differences just between 20 and $38^{\circ} \mathrm{C}$. Probably the lack of significant differences after $38^{\circ} \mathrm{C}$, is determined by the thermal fragmentation of the polymer chain (Ta), that make this fragments unable to adsorbed with casein, an important proportion of Ta being affected by the first shock of heat. The correlation within Ta and non-adsorbed polyphenols on casein is the result of passage of the truncated Ta chains in non- adsorbed polyphenols fraction on casein. The drying and storing process is an important step for grape pomace usage as a feed additive because we demonstrated that the Ta presents a high level of degradation especially between 20 and $38^{\circ} \mathrm{C}$.
\end{abstract}

Keywords: anthocyanins, grape pomace, tannins, polyphenols

\section{INTRODUCTION}

The grape pomace is a by-product generated during the winemaking process, in a very high quantity made up of seeds, skins and stalk fragments. According to the International Organization of Vine and Wine (OIV) this byproduct is about $20 \%$ of the total weight of the harvested grapes (Vitis vinifera) (Sui et al., 2014).

Studies on the chemical composition of the grape pomace revealed that in addition to its content in protein, fiber, sugars, minerals and fats (Aslanian et al., 2011) it contains high amounts of polyphenols (Alonso et al., 2002; Bonilla et al., 1999), which justify the use of this by-product in animal nutrition (Baumgärtel et al., 2007; Zalikarenab et al., 2007).

Polyphenols accumulate in the solid parts of the grapes, in skins $(28-35 \%)$ seeds $(60-70 \%)$ and stalks (less than 10\%) which pass, after the maceration-fermentation process into the grape juice and wine, up to $50 \%$ of them, the rest remaining in the grape pomace.

Chemically speaking, phenols are substances, which have in their structure an aromatic ring (benzene) with one or more hydroxyl $(-\mathrm{OH})$, including functional derivatives.

Over 8000 phenolic compounds were identified and according to the similarity of their chemical structures, they were classified into classes and subclasses. The grapes have mainly anthocyanins, flavones, flavonols, stilbenes (resveratrol) and phenolic acids (Dopico-Garcia et al., 2008).

Numerous studies have shown the beneficial effects of polyphenols including the antioxidant, antibacterial, anti-inflammatory and anti-metano- 
genic ones, as well as a protective role against the degenerative diseases being able to present thus a great interest in animal health and nutrition (Brenes et al., 2008; Goni et al., 2007; Saurai, 2014).

If fresh, the grape pomace has a high water content (over 60\%), which does not allow its preservation for a long time. Likewise, the presence of sugars increases the alteration process of this by-product, thus requiring a preliminary drying to prevent the degradation processes caused by the attack of the microorganisms from the environment.

To dry the grape pomace in well-ventilated areas or by exposure to the sun (Guemour et al., 2010) can be a way to store it, for a better valorization in the animal nutrition. The grape pomace drying may be carried out in such a way that the content of polyphenols to be kept as much as possible. In the published literature, there are few data on the influence of the drying temperature on the content of total polyphenols, anthocyanins and tannins.

It was proven that the content of polyphenols from grapes degrades during the drying process. Similarly, the study carried out by Larrauri et al., (1997) showed that drying the grape pomace at temperatures below $60^{\circ} \mathrm{C}$ did not cause a very high degradation of the polyphenols, but the $100^{\circ} \mathrm{C}$ drying caused a rather large decrease of these compounds.

The objective of the hereby study was to identify the degree of degradation of the polyphenols during the drying stage of the grape pomace at different temperatures.

\section{MATERIALS AND METHODS}

The fresh grape pomace (FGP) resulted from the red wine grapes (Black Maiden) vinification process was obtained from the Research Station (V. Adamachi farm) of the USAMV Iasi being made up of skins, seeds and stalk fragments.

The grape pomace was dried in different ways: at room temperature $\left(20^{\circ} \mathrm{C}\right)$, for five days, or oven drying at $38^{\circ} \mathrm{C}$ and $50^{\circ} \mathrm{C}$ respectively for three days.

Given the heterogeneity of this by-product itwas tried for the test evidence to be more homogeneous and representative of the whole biomass. The samples from the laboratory experiments were obtained by the fractionation of the aggregate samples, using the quartering method.
To determine the content of polyphenols, the samples were ground in the mechanical laboratory mill Grindomix GM 200 until we obtained a powder with particles of $1 \mathrm{~mm}$ diameter, according to the SR ISO 6498: 2001 standard.

Chemical reagents. All reagents used throughout the work were of analytical purity. Folin-Ciocalteu reagent (FCR, Merck, Germany) as a chromogenic agent were used; Casein (Merck, Germany) as a adsorbed agent; Sodium carbonate decahydrate (Chemical Company, Romania); Anhydrous Gallic acid (Merck, Germany); concentrated hydrochloric acid (37\%) and ethylic alcohol (96\%) were purchased from Chemical Company, Romania.

Determination of total polyphenols, tannins and anthocyanins. To determine the total content of polyphenols and tannins, the grape pomace samples were previously degreased to remove the lipophilic substances (oils, acids, vitamins, triglycerides etc.) present in the grape pomace. The extraction of these substances from the vegetal material was performed using the petroleum ether by the Soxhlet classical method.

The total polyphenols (TP\%) and tannins (Ta\%) in the alcoholic extracts (50\%) obtained of the degreased grape pomace samples according to the patent (Bişboacă, 2012) were determined by Folin-Ciocalteu method described by Singleton and Rossi (1965), hereinafter briefly presented.

The degreased grape pomace powder samples (3 g) were extracted with $50 \mathrm{ml}$ of ethanol aqueous solution of $50 \%(\mathrm{v} / \mathrm{v})$ for 24 hours at thermostat at $45^{\circ} \mathrm{C}$ with intermittent shaking (Bişboacă, 2012). After 24 hours of thermostating, the extracts were cooled and centrifuged at 5000 rpm for 15 minutes to recover the supernatants (basic sample solution, BSS). To determine the tannins we used the scheme proposed by Tarcau et al., (2013), two milliliters of BSS were sampled in an Erlenmeyer flask (50 mL) where $8 \mathrm{~mL}$ of water and $10 \mathrm{~mL}$ of acetate were introduced (S1 solution 1). $10 \mathrm{~mL}$ were taken from $\mathrm{S} 1$ where 50 mg of casein were added and stirred for $45 \mathrm{~min}$, (adsorption of the tannins). After the adsorption on the casein of the tannins and filtration, solution 2 (S2) was obtained. Of each S1 and S2 solution 1 $\mathrm{mL}$ was taken to determine the total polyphenols using the Singleton and Rossi, (1965) method, in which $3 \mathrm{~mL}$ of Folin-Ciocalteu reagent (FCR) were added, $20.0 \mathrm{~mL}$ of $\mathrm{Na}_{2} \mathrm{CO}_{3} 10 \mathrm{H}_{2} \mathrm{O}$ solution having a 
Tab.1. The content of total polyphenols, tannins and anthocyanins (mean $\pm \mathrm{SD}$ in $\mathrm{g} / \mathrm{kg}$ ) depending on the drying temperature

\begin{tabular}{ccccc}
\hline $\begin{array}{c}\text { Drying temperature } \\
\left({ }^{\circ} \mathrm{C}\right)\end{array}$ & $\begin{array}{c}\text { Total } \\
\text { polyphenols }(\mathrm{g} / \\
\mathrm{kg})\end{array}$ & $\begin{array}{c}\text { Tannis } \\
(\mathrm{g} / \mathrm{kg})\end{array}$ & $\begin{array}{c}\text { Non-adsorbed polyphenols } \\
\text { on casein }(\mathrm{g} / \mathrm{kg})\end{array}$ & $\begin{array}{c}\text { Anthocyanins } \\
(\mathrm{g} / \mathrm{kg})\end{array}$ \\
\hline $20^{\circ} \mathrm{C}$ & $21.68 \pm 0.50^{\mathrm{a}}$ & $15.34 \pm 0.39^{\mathrm{a}}$ & $6.19 \pm 0.15^{\mathrm{a}}$ & $0.42 \pm 0.005^{\mathrm{a}}$ \\
\hline $38^{\circ} \mathrm{C}$ & $19.38 \pm 0.10^{\mathrm{b}}$ & $11.63 \pm 0.95^{\mathrm{b}}$ & $6.76 \pm 0.95^{\mathrm{b}}$ & $0.33 \pm 0.002^{\mathrm{b}}$ \\
\hline $50^{\circ} \mathrm{C}$ & $17.92 \pm 0.46^{\mathrm{c}}$ & $11.04 \pm 0.34^{\mathrm{NS}}$ & $6.87 \pm 0.17^{\mathrm{c}}$ & $0.31 \pm 0.002^{\mathrm{c}}$ \\
\hline Anova $\mathrm{p}$-value & $9.02 \mathrm{E}-49$ & $1.5 \mathrm{E}-22$ & $1.16 \mathrm{E}-08$ & $3.36 \mathrm{E}-08$ \\
\hline
\end{tabular}

Note: Values marked by different letters (a-c) are significantly different (T-test, $\mathrm{p}<0.05$ ); ${ }^{\text {NS}}$ Non-significant differences; $\mathrm{n}=3 ;{ }^{*}$ Anova single factor $(\mathrm{p}<0.05)$

concentration of $10 \%$. The absorbance was measured after $60 \mathrm{~min}$ at a wavelength of $760 \mathrm{~nm}$.

The content of total polyphenols expressed as gallic acid gram equivalents per $\mathrm{kg}$ (GAE g/ $\mathrm{kg}$ ), using the standard curve in the range of $0.01 \mathrm{mg}$ to $0.1 \mathrm{mg} / \mathrm{mL}$. The calibration equation for gallic acid was $y=0.9343 x-0.0103$, being observed a good linearity $(\mathrm{R} 2=0.9995)$.

The differences between the total polyphenols content determined in S1 and S2 (total polyphenols - the non-adsorbed polyphenols on casein) correspond to the concentration of tannins in the samples analyzed. Three determinations for each sample of red grape pomace were performed.

To determine the anthocyanin content of the grape pomace samples, the evaluation method of red grapes (ITV method) was used. In the experiment were used $5 \mathrm{~g}$ of dried grape pomace being added $85 \mathrm{~mL}$ of $0.1 \% \mathrm{HCl}$ solution and $15 \mathrm{~mL} \mathrm{96 \%} \mathrm{ethanol.} \mathrm{After} \mathrm{mixing,} \mathrm{the} \mathrm{samples}$ were soaked for an hour being stirred every 15 minutes at room temperature. The extracts were spectrophotometrically analyzed at $520 \mathrm{~nm}$.

The anthocyanin content was calculated according to the customized ITV method using the following formula: total anthocyanins $\mathrm{mg} / \mathrm{kg}$ $=$ Anthocyanins $(\mathrm{mg} / \mathrm{L}) \mathrm{x}$ [grape pomace weight + 100/grape pomace weight].

Statistical analysis. Analyses were carried out in triplicate. Means and standard deviations were calculated for total polyphenols, tannins and anthocyanins concentrations.

The obtained results were statistically processed using the single factor ANOVA test ( $p$ $<0.05)$, Fisher's test and Student's t-test to highlight the significant differences between the drying temperatures.

\section{RESULTS AND DISCUSSION}

The results (Tab.1) showed a significant decrease in TP content, Ta and An $(p<0.05)$ at the same time with the increase of the temperature during the grape pomace drying process.

Using the crude polyphenol extracts to determine the tannins it was found a decrease in the content of Ta and an increase in the content of non-adsorbed polyphenols in the casein extracts. This would imply a degradation of the tannins, depending on the temperature, which may lead to non-adsorbed casein compounds. In support of this assumption the TP values come being determined after the adsorption on casein (Tab. 1).

The results showed a significant reduction in the content of polyphenols especially to the temperature variations: $20^{\circ} \mathrm{C}$ and $38^{\circ} \mathrm{C}$, verified statistically using the F-test and t-test to observe significant differences between the drying temperatures. Thus, in the case of the total polyphenols very significant differences resulted $(\mathrm{p}<0.001)$ between the samples dried at $20^{\circ} \mathrm{C}$ and $38^{\circ} \mathrm{C}$ and respectively between $38^{\circ} \mathrm{C}$ and $50^{\circ} \mathrm{C}$, allowing to calculate a regression curve

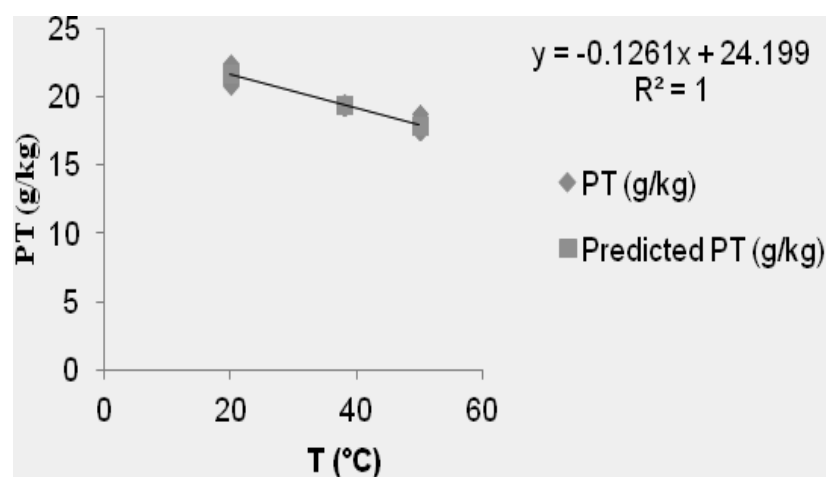

Fig. 1. Regression curve obtained for total polyphenols 
(Fig. 1), using the relative values resulted after the determinations of the total polyphenols.

The resulting regression equation $(y=-0.1261 x$ +24.199 ) was used to estimate the percentage of the total polyphenols degradation depending on the temperature (Fig. 2).

The grape pomace dried at $20^{\circ} \mathrm{C}$ was considered to have the highest concentration $(100 \%)$ of total polyphenols compared to the other grape pomace samples dried at different temperatures in the oven. Thus, in order to calculate the prediction of thermal degradation, each value obtained from the calculation equation

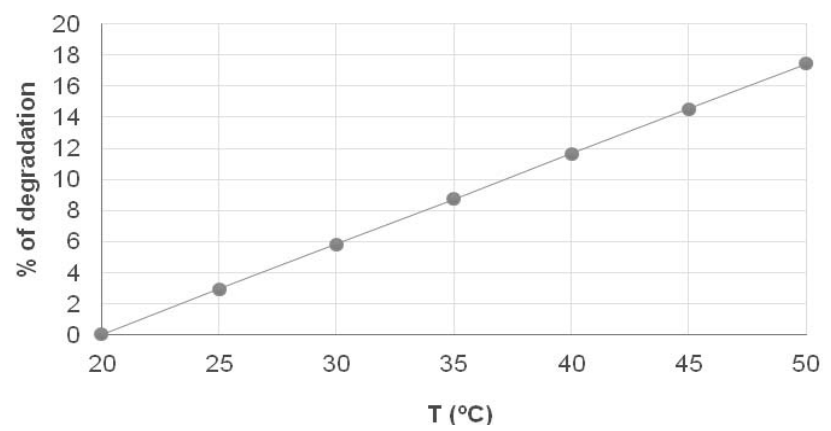

Fig. 2. Total polyphenols degradation prediction

was reported at the highest amount, that is the maximum amount of total polyphenols obtained in the case of grape pomace dried at $20^{\circ} \mathrm{C}$.

The graphical representation (Fig. 2) shows that the degradation of the total polyphenols increases progressively with the temperature increase; the maximum value of degradation is of $17.45 \%$ for the temperature of $50^{\circ} \mathrm{C}$.

Using the same calculation manner in the case of tannins as well, significant differences could be observed, with a confidence interval of more than $99.9 \%(\mathrm{p}<0.001)$, only between the drying variations at $20^{\circ} \mathrm{C}$ and $38^{\circ} \mathrm{C}$ (Fig. 3).

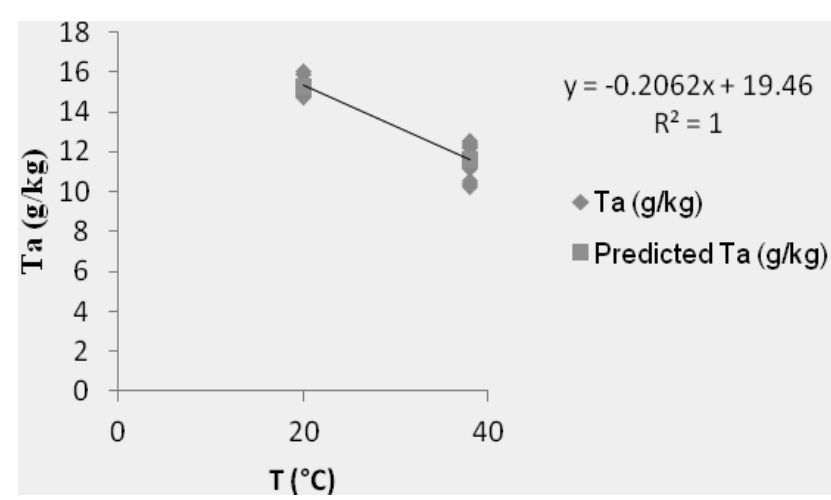

Fig. 3. Regression curve obtained for tannins
In the drying variants at temperatures of $38^{\circ} \mathrm{C}$ and $50^{\circ} \mathrm{C}$, the values showed a $99 \%$ confidence interval $(\mathrm{p}<0.05)$, which does not allow to calculate a regression curve in order to estimate the degree of tannins degradation.

Based on the relative values of the tannins resulting in the drying variants at $20^{\circ} \mathrm{C}$ and $38^{\circ} \mathrm{C}$

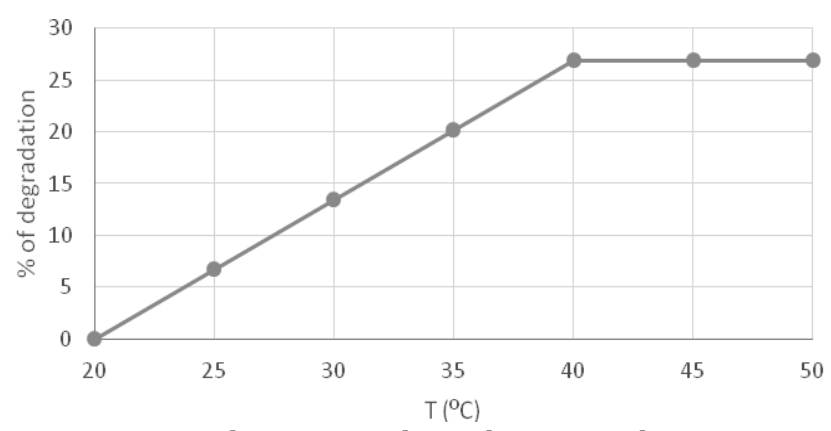

Fig. 4. The tannins degradation prediction

the regression equation $(y=-0.2062 x+19.46)$ was obtained and was used to estimate the degree of tannins degradation (Fig. 4).

Figure 4 shows a gradual degradation of the tannins up to a temperature of $40^{\circ} \mathrm{C}$, the maximum value of degradation being of $26.89 \%$, after that the values remain constant.

In the case of the anthocyanins highly significant values $(p<0.001)$ were obtained between the drying temperatures: $20^{\circ} \mathrm{C}$ and $38^{\circ} \mathrm{C}$ and respectively $38^{\circ} \mathrm{C}$ and $50^{\circ} \mathrm{C}$; thus were considered all the drying variants to calculate the regression line (Fig. 5) and to estimate the anthocyanins degradation prediction depending on the temperature (Fig. 6).

The graphical representation (Fig. 6) shows a progressive increase in anthocyanin degradation increasing the drying temperature; the maximum degradation value is of $28.23 \%$ at a temperature of $50^{\circ} \mathrm{C}$.

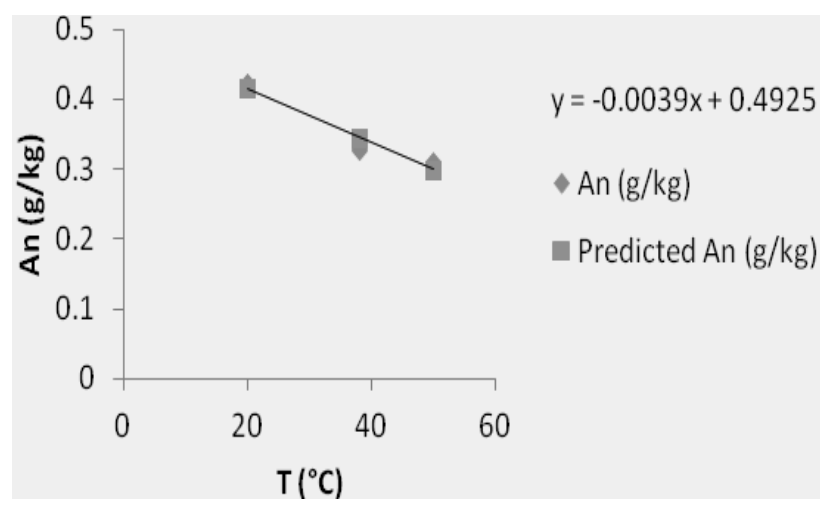

Fig. 5. Regression curve obtained for anthocyanins 


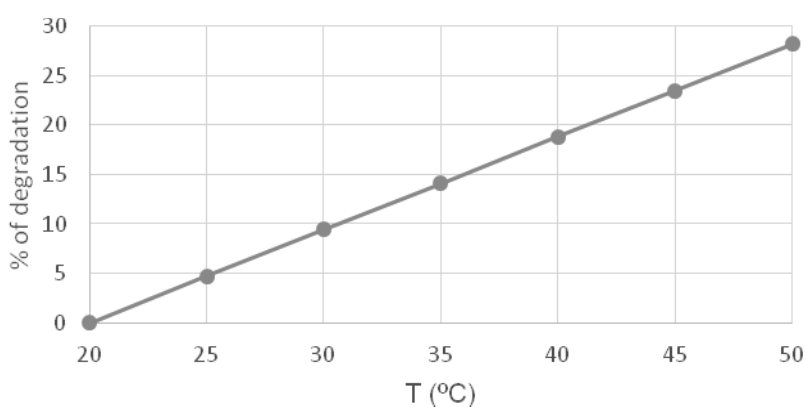

Fig. 6. Anthocyanins degradation prediction

Given the fact that there is no single method to determine the total polyphenols, tannins and anthocyanins, as well as standard methods to dry the grape pomace, the data obtained in our research are difficult to be compared with the few data found in the published literature (Khanal, et al., 2009; Khanal, et al., 2010; Patras et al., 2010), on the effect of the drying temperature on the polyphenols, but we consider they bring supplementary information to this effect.

\section{CONCLUSION}

The study found that total polyphenols and anthocyanins content decreases significantly when the drying temperature is increased at $20^{\circ} \mathrm{C}$, $38^{\circ} \mathrm{C}$ and $50^{\circ} \mathrm{C}$.

In case of the tannins, very significant differences occurred between the variants drying: $20^{\circ} \mathrm{C}$ and $38^{\circ} \mathrm{C}$. The tannins degradation would lead to non-adsorbed casein compounds, fact supported by the polyphenols increase in the casein extracts.

The hereby study suggests that the optimum temperature to dry the grape pomace in order to preserve the compounds with biologically active properties for use in animal nutrition is $20^{\circ} \mathrm{C}$. This aspect is supported by repeating the measurements and the performed statistical calculation.

\section{REFERENCES}

1. Alonso A, D Guillean, C Barroso, B Puertas and A Garcia (2002). Determination of antioxidant activity of wine byproducts and its correlation with polyphenolic content. Journal of Agric. and Food Chemistry, 50: 5832-5836.

2. Aslanian A, A Asadi Dizaji, P Farhoomand, H Aghdam Shahryar, N Maheri Sis. and S Rouhnavaz (2011). Characterization of the nutritive value and protein system in white and red grape (Vitis vinifera sp.) pomace. Research Journal of Biological Sciences 6 (7): 298-303.
3. Baumgärtel T, H Kluth, K Epperlein and M Rodehutscord, (2007). A note on digestibility and energy value for sheep of different grape pomace. Small Ruminant Research 67: 302-306.

4. Bișboacă Simona Elena (2012). Patent, A process to obtain the polyphenols from grape pomace, R0125704 B1, 1-5.

5. Bonilla F., M Mayen, J Merida and M Medina, (1999). Extraction of phenolic compounds from red grape marc for use as food lipid antioxidants. Food Chemistry 66: 209-215.

6. Brenes A, A Viveros, I Goni, C Centeno, SG Sayago-Ayerdi, I Arija and F Saura-Calixto (2008). Effect of grape pomace concentrate and vitamin $\mathrm{E}$ on digestibility of polyphenols and antioxidant activity in chickens. Poultry Science 87: 307-316.

7. Goni I, A. Brenes C, Centeno A, Viveros F, Saura-Calixto, A. Rebole, I. Arija and R. Esteve, (2007). Effect of dietary grape pomace and vitamin $\mathrm{E}$ on growth performance, nutrient digestibility and susceptibility to meat lipid oxidation in chickens. Poultry Science 86: 508-516.

8. Dopico-Garcia, M.S.; A. Fique, L. Guerra, J.M. Afonso, O. Pereira, P. Valentao, P.B. Andrade and R.M. Seabra, (2008). Principal components of phenolics to characterize red Vinho Verde grapes: anthocyanins or non-coloured compounds Talanta 75: 1190-1202.

9. Guemour, D., C. Bannelier, A. Dellal and T. Gidenne, (2010). Nutritive value of sun-dried grape pomace incorporated at a low level in complete feed for the rabbit bred under Magrebian conditions. World Rabbit Science, 18: 17-25.

10. Khanal, R.C., L.R. Howarda and R.L. Prior, (2009) Procyanidin content of grape seed and pomace and total anthocyanin content of grape pomace as affected by extrusion processing. Journal of Food Science, Vol 74 (6): 174-182.

11. Khanal, R.C., L.R. Howarda and R.L. Prior, (2010). Effect of heating on the stability of grape and blueberry pomace procyanidins and total anthocyanins. Food Research Int. 43: 1464-1469.

12. Larrauri, J.A., P. Ruperez and F. Saura Calixto (1997). Effect of drying temperature on the stability of polyphenols and antioxidant activity of red grape pomace peels. Journal of Agricultural and Food Chemistry, 45 (4): 1390-1393.

13. Patras, A., N.P. Brunton, C. O'Donnell and B.K. Tiwari (2010). Effect of thermal processing on anthocyanin stability in foods; mechanims and kinetics of degradation. Food Science and Technology. 21: 3-11.

14. Singleton, V.L. and J.A. Rossi. (1965). Colorimetry of total phenolics with phosphomolybdic - phosphotungstic acid reagents. American. Journal of Enology and Viticulture, 16: 144-158.

15. Sui, Y., J.Yang, Q. Ye, H. Li and H. Wang (2014). Infrared, Convective, and Sequential Infrared and Convective Drying of Wine Grape Pomace. Drying Technology: An International Journal, 32 (6): 686-694.

16. Surai, P.F., (2014). Polyphenol compounds in the chicken/ animal diet: from the past to the future, Journal of Animal Physiology and Animal Nutrition, 98: 19-31. 
17. Tarcau, D., Vîntu V., Samuil C. and Man-Cucu S, (2013). Polyphenolic composition of a permanent pasture under influence of organic fertilization, University of Agricultural Sciences and Veterinary Medicine of Iasi, Romania, Vol. 59: 98-102.

18. Zalikarenab, L.R., R. Pirmohammadi and A. Teimuriyansari, (2007). Chemical composition and Digestibility of dried white and red grape pomace for ruminants. J. Anim. Vet. Adv., 6(9): 1107-1111.

19. Method for the assessment of grape maturation (ITV Method). Cod: Met_EVMS_07_2013; Edition 02, 2-5.

20. *** SR ISO 6498 (2001) Animal feeding stuffs - Preparation of test samples. 